\title{
Prevalence of asymptomatic malaria infections in selected military camps in Tanzania
}

Akili K. Kalinga ${ }^{1,2^{*}}$, Reginald A. Kavishe ${ }^{2}$, Deus S. Ishengoma ${ }^{3}$, Gibson B. Kagaruki ${ }^{1}$, Clement N. Mweya $^{4}$, Lucky Temu ${ }^{5}$, Sarah Chiduo ${ }^{5}$, Christopher Mswanya ${ }^{6}$, Charles Mwanziva ${ }^{6}$, Saidi Mgata ${ }^{5}$, Lucas Mahikwano ${ }^{5}$, George $\mathrm{Amoo}^{7}$, Colin $\mathrm{Ohrt}^{8}$, Edwin Kamau', Mark Hickman ${ }^{9}$, Norman Waters ${ }^{9}$, Mara Kreishman-Deitrick ${ }^{9}$, Brian Vesely ${ }^{9}$

${ }^{1}$ National Institute for Medical Research, Tukuyu Centre, Tukuyu, Tanzania

${ }^{2}$ Kilimanjaro Christian Medical University College and Kilimanjaro Clinical Research Institute, Moshi, Tanzania

${ }^{3}$ National Institute for Medical Research, Tanga Centre, Tanga, Tanzania

${ }^{4}$ University of Dar es salaam, Mbeya College of Health and Allied Sciences, Mbeya, Tanzania

${ }^{5}$ Henry Jackson Foundation Medical Research International, Dar es Salaam, Tanzania

${ }^{6}$ Tanzania Peoples Defence Forces, Dar es Salaam, Tanzania

${ }^{7}$ Forgyn Health Systems Consultants, Washington DC, USA

${ }^{8}$ Consortium for Health Action, Phnom Penh, Cambodia

${ }^{9}$ Walter Reed Army Institute of Research, Washington DC, USA

\section{Abstract}

Background: Despite a decrease in malaria burden reported between 2000 and 2015, an increasing trend of malaria transmission has been recently reported in some endemic countries including Tanzania. Periodic monitoring to identify pocket areas for asymptomatic Plasmodium falciparum infection is vital for malaria elimination efforts. The objective of this study was to determine prevalence of asymptomatic malaria infections among military recruits in selected camps in Tanzania.

Methods: A cross-sectional study was conducted in 2015 at four military camps (Bulombora, Mgambo, Ruvu, and Rwamkoma) of National Service located in regions with varying malaria endemicity in Tanzania. Finger prick blood samples collected from asymptomatic military recruits who had been at the camps for over two months were simultaneously tested using microscopy and malaria rapid diagnostic tests (mRDTs) to detect malaria parasite infections.

Results: Malaria parasite prevalence among asymptomatic recruits was $20.3 \%$ and $19.4 \%$ by microscopy and mRDT respectively. There was moderate agreement (Kappa=0.724) between microscopy and mRDT test results. A significant difference $(p<0.001)$ of malaria parasite prevalence among the four study camps was observed; ranging from $1.9 \%$ in Bulombora to $39.4 \%$ in Rwamkoma. The geometric mean parasite density was

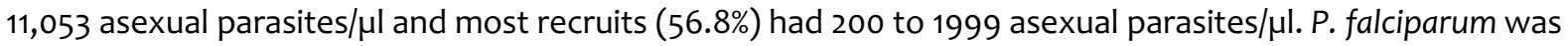
the predominant (99.2\%) malaria parasite species.

Conclusion: Our study found high prevalence of asymptomatic malaria infections among military recruits in the selected camps, and this varied from one camp to another. The study has highlighted that public residence institutions such as military camps can be potential hotspots for malaria infection and therefore should not be skipped in routine national malaria surveillance system for monitoring trends of infections

Keywords: Malaria, prevalence, asymptomatic, recruits, military camps, Tanzania

\section{Introduction}

Until 2000 malaria was a devastating disease causing 86\% of all global deaths among children under five years of age (WHO \& UNICEF, 2015). Efforts to combat malaria through the Millennium Development Goals (MDGs) were implemented and included prompt diagnosis and treatment, high coverage of insecticide-treated mosquito nets/long lasting insecticidal nets (ITNs/LLINs), larval control and indoor residual spraying (WHO \& UNICEF, 2015). Other interventions included intermittent preventive treatment in infants (IPTi) (Dicko et al., 2008; Kweku et al., 2008) and

\footnotetext{
*corresponding Email: kalingaaka@yahoo.com
} 
pregnant women (IPTp) in areas of stable/seasonal malaria transmission (Gething et al., 2014; WHO, 2016).

Through global concerted control efforts, countries successfully reversed malaria incidence burdens (Bhatt et al., 2015; WHO, 2010C) with cases declining by an estimated $37 \%$ and mortality rate reduced by $60 \%$ (WHO \& UNICEF, 2015). In Africa, malaria prevalence and incidence decreased by almost $50 \%$ and by about $40 \%$ between 2000 and 2015 respectively (Bhatt et al., 2015). The global decline in malaria death rate from over $80 \%$ in 2000 to less than $30 \%$ in 2015 is indicative of these efforts to fight against malaria. In Tanzania, a significant reduction in prevalence of $P$. falciparum and burden of malaria was similarly observed (Ishengoma et al., 2013; Kanté et al., 2014; Mmbando et al., 2010). For example, prevalence of malaria by mRDT among under-fives declined from $18.1 \%$ in 2008 to $9.7 \%$ in 2012 (NBS (TZ) \& Macro int., 2009; TACAIDS et al, 2013). Between 2003 and 2008, the prevalence of malaria infection decreased dramatically from $78.4 \%$ to $24.0 \%$ in the lowland and from $24.7 \%$ to $6.5 \%$ in the highland communities of Korogwe district in north-east Tanzania (Mmbando et al., 2010) Malaria prevalence also declined from $70 \%$ in 1985 to 4.8\% in 2010 in Rufiji district in eastern Tanzania (Färnert et al, 2015)

Despite the reported global reduction in malaria burden between 2000 and 2015, there has been a recent halt in the decline of malaria morbidity and mortality. An increasing trend in malaria incidence has been observed in some countries with about 219 million cases in 2017 compared to 217 million in 2016, and 211 million in 2015 (WHO, 2018). The same trend has been observed in some African countries with pockets of malaria which require urgent interventions (Nkumama et al, 2017). According to the WHO report of 2018, Tanzania is among the 11 countries with the highest burden of malaria in the East and Central African region and is among 7 countries that accounted for $53 \%$ of all global malaria deaths in 2017 (WHO, 2018).

Periodic monitoring to identify pocket areas for $P$. falciparum infections is vital for malaria elimination efforts. Since good proportion of $P$. falciparum infections are asymptomatic in most endemic countries (Males et al, 2008; Singh et al., 2014), they are responsible for maintaining parasite transmission cycle in presence of mosquitoes vectors (Gbalégba et al., 2018; Kimbi, 2012; Mehrizi et al., 2012). In Tanzania, there are some areas including military setting where malaria incidence rates are still high despite recent reported fall in morbidity and mortality rates. Passive malaria surveillance data in military health facilities showed high malaria positivity rate $(48.4 \%)$ by microscopy in Mgambo camp (Kalinga et al., 2018) and parasite positivity rates increased from $22.9 \%$ in 2013 to $29.3 \%$ in 2014 and to $37.1 \%$ in 2015 in eight military clinics (Kalinga et al, 2016: Unpubl). Military camps receives recruits from different areas with varying malaria endemicity and may carry malaria parasite infections and perpetuate transmission in the camps and surrounding areas. Moreover, recruits from different malaria epidemiological settings have varying immunological profiles that also defines susceptibility levels to malaria infection in camps located in malaria endemic areas. Due to large influx of recruits in military camps, transmission of malaria parasites is likely to occur compared to general population in the surrounding areas. Unfortunately, no study has been conducted in military settings to estimate prevalence of malaria parasites infections because military camps are not included during routine national surveys and hence are without data. Therefore, this study was conducted to measure the current rate of asymptomatic carriage among recruits to give better understanding of infection rates in military setting which is among public health residence institutions. The findings of this study will be helpful in informing the national malaria control program for broadening malaria surveillance systems to addressing gaps in malaria elimination interventions.

\section{Materials and methods \\ Study area}

The study was conducted in four selected military camps of the National Service commonly known as "Jeshi la Kujenga Taifa (JKT)" located in four geographical zones across Tanzania. The four camps included Rwamkoma, Mgambo, Ruvu and Bulombora located in malaria endemic regions of 
Mara, Tanga, Ruvu, Pwani and Kigoma of the zones of Lake, North, East and West respectively (Fig 1). These regions have variations in malaria endemicity due to geographical locations; Mara and Kigoma regions are located upcountry areas while Tanga and Pwani regions are located on the Indian Ocean belt (NMCP \& WHO, 2013)

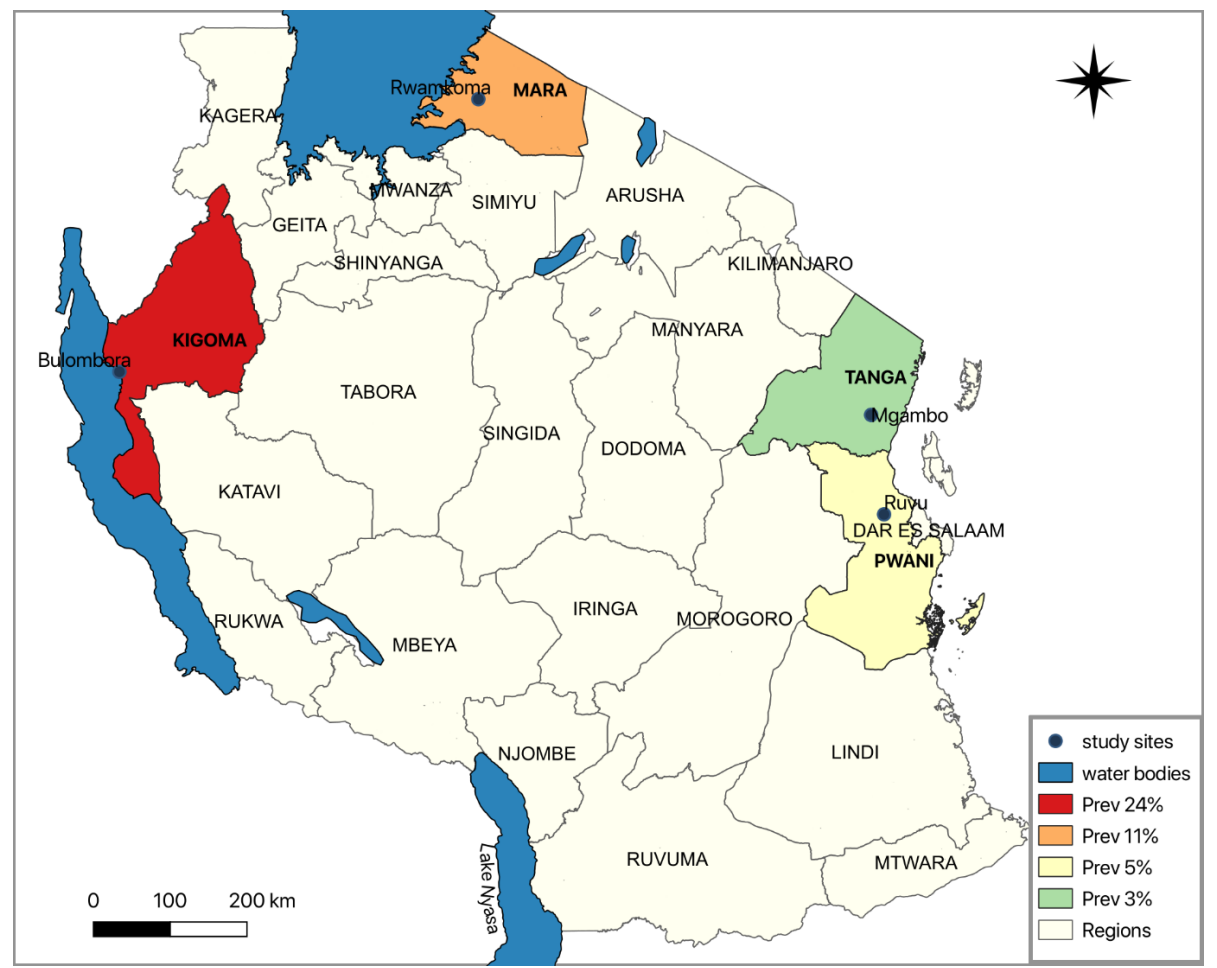

Fig 1. Map of Tanzania showing study regions, camps and prevalence data (MOHCDGEC et al, 2018) (Map generated using shape files and data using qGIS version 3.2 (Team, 2018)

\section{Study design}

Cross-sectional surveys were done in 2015 between June and September which is a period of high malaria transmission intensity in most study areas as described previously(NMCP \& WHO, 2013) in order to capture peak transmission.

\section{Study population and sample size}

The study population were military recruits who were adolescents just completed advanced secondary school or college across the country, attending the national service on compulsory scheme for a period of three to six months. The recruits were selected because are originating from different regions with different malaria endemicity. In particular, those from low malaria transmission patterns are more attacked by malaria infections and some succumbs deaths upon reporting at military camps located in malaria endemic areas.

A minimum sample size(n) of 800 participants was calculated using a single proportion formula $\left(n=Z^{2} p(1-p) / \Sigma^{2}\right)$ whereby the population prevalence $(p)$ estimated to be 0.25 from average parasite positivity rate of eight camps (Kalinga et al, 2016 Unpubl.), level of confidence(Z) of 1.96 and margin of error $(\Sigma)$ of 0.03 at $95 \%$ confidence interval. However, due to availability of study participants, 886 asymptomatic recruits were sampled for determining malaria parasite prevalence

\section{Sampling of study participants}

The sampling frame were military recruits who had been at the selected military camps for over two months. Equal number of recruits and by sex was considered at each participating military 
camp. A total of 1000 recruits (about 255 from each camp) were selected using systematic random sampling method from registers of established sub groups called "company". The recruits had their 24-hour history assessed to rule out clinical symptoms of malaria. Asymptomatic individuals (defined as digital axillary body temperature less than $37.5^{\circ} \mathrm{C}$ ) were confirmed by measuring their body temperature. Only 866 asymptomatic JKT recruits were included while 134 recruits who were found to be symptomatic were excluded from the study.

\section{Data collection}

In this study, Giemsa-stained microscopy and malaria rapid diagnostic test (mRDT) were both used to detect malaria parasite infection in order to complement errors associated with either of the diagnostic methods(Ugah et al., 2017b). An mRDT chosen for diagnosis is SD Bioline Malaria Antigen Pf/pan (made by Standard Diagnostics, in Hagal-Dong, Korea) mRDT that detects $P$. falciparum histidine-rich protein 2 (PfHRP2) and others (Pan) P. falciparum Lactate dehydrogenase (PfLDH). This mRDT is recommended by the Tanzanian National Malaria Control Programme for malaria diagnosis countrywide since 2012 (TACAIDS et al, 2013). A finger prick blood sample was collected from recruits who provided written informed consent. The mRDTs were processed and interpreted visually by trained laboratory personnel according to manufacturer's instructions. Blood samples for Giemsa microscopy were prepared as described previously (WHO, 2010b). Thick and thin blood films for identification and quantification of malaria parasites were examined microscopically for the presence of malaria parasites. To confirm positive films, asexual parasites were counted against 200 white blood cells (WBCs) Assuming that each microlitre $(\mu \mathrm{L})$ of blood contains $8,000 \mathrm{WBC}$, asexual parasite densities were calculated by multiplying the parasite counts by 40 as set by the WHO (WHO, 2010a). Malaria species were detected and differentiated using thin blood smears as previously described (WHO, 2010a, 2010b). A blood smear was considered negative if no parasites was observed at 200 high-power fields.

Quality control was done for microscopy to ensure that results obtained are credible. The smears were prepared, stained and read for the first time at military health facilities by laboratory assistants who apart from being experienced malaria microscopists, received two weeks' special refresher training to be acquainted with new malaria microscopy techniques before participating in the study. Blood smears were later transferred to the base where a second reading was performed by a second reader who was experienced microscopist. Both readers were blinded of mRDT results. Discordant results between the two readers were break-tied by a laboratory technologist based at the base of the project.

\section{Data management}

Diagnostic data from both microscopy and mRDT readings were double entered into Epidata Version 3.1; then exported into Statistical Package for Social Sciences version 23 for Windows (SPSS Inc, Chicago, USA) and Stata version 15 (STATA Corp Inc., TX, USA) for cleaning and analysis. The association between categorical variables was tested by Pearson Chi-square (for two by two tables) or Chi-square of trend (for two by many generated by default by SPSS software). Association or difference between variables was considered statistically significant if $p$-value was less than $5 \%$. The extent of agreement between interraters i.e. the gold standard (microscopy) and the test tool (mRDT) was measured using Kappa values(McHugh, 2012) as either none(0.0-0.20), minimum (0.20-0.39), weak(0.40-0.59), moderate(0.60-0.79), strong(0.80-0.90), and perfect agreement $(>0.90)$

\section{Results}

\section{Demographic characteristics}

A total of 866 asymptomatic recruits were tested for malaria parasitaemia. Majority of participants were females (61.3\%) and mostly aged >20years (59.6\%) with mean age of $21.0( \pm 1.3 \mathrm{SD}$ ) years; 
ranging from 18 to 29 years. More participants (29.0\%) were recruited at Rwamkoma; which also had a larger proportion of female (80.9\%) participants compared to other camps.

The overall malaria parasite prevalence was $20.3 \%$ and $19.4 \%$ by microscopy and mRDT respectively (Table 1). Malaria parasite prevalence ranged from $1.9 \%$ in Bulombora to $39.4 \%$ in Rwamkoma. P. falciparum was the predominant malaria species constituting $99.2 \%$ while only $0.8 \%$ of samples had mixed infections of $P$. falciparum and $P$. malariae.

Table 1: Demographic characteristics of study participants and key descriptive results

\begin{tabular}{|c|c|c|c|c|c|}
\hline \multirow[b]{2}{*}{ Variable } & \multicolumn{5}{|c|}{ Military camps } \\
\hline & $\begin{array}{l}\text { Bulombora } \\
(\mathrm{n}=215)\end{array}$ & Mgambo $(n=200)$ & $\begin{array}{l}\text { Ruvu } \\
(n=200)\end{array}$ & $\begin{array}{l}\text { Rwamkoma } \\
(\mathrm{n}=251)\end{array}$ & $\begin{array}{l}\text { All } \\
(n=866)\end{array}$ \\
\hline \multicolumn{6}{|l|}{ Sex, n(\%) } \\
\hline Male & $91(42.3)$ & $98(49.0)$ & $98(49.0)$ & 48(19.1) & $335(38.7)$ \\
\hline Female & $124(57.7)$ & $102(51.0)$ & $102(51.0)$ & 203(80.9) & $531(61.3)$ \\
\hline \multicolumn{6}{|l|}{ Age } \\
\hline Range(n) & $18-29$ & $18-27$ & $18-27$ & $19-26$ & $18-29$ \\
\hline Mean (SD) & $21(1.3)$ & $20.8(1.3)$ & $20.8(1.3)$ & $21.3(1.3)$ & $21.0(1.3)$ \\
\hline \multicolumn{6}{|l|}{ Prevalence, $\mathrm{n}(\%)$} \\
\hline By microscopy & $4(1.9)$ & $62(31.0)$ & $11(5.5)$ & $99(39.4)$ & $176(20.3)$ \\
\hline By mRDT & $3(1.4)$ & $59(29.5)$ & $9(4 \cdot 5)$ & $97(38.6)$ & $168(19.4)$ \\
\hline \multicolumn{6}{|c|}{ Parasite density, (asexual par/ $\mu \mathrm{l}$ ) } \\
\hline Range & $600-6080$ & $80-48800$ & $160-616040$ & $80-229320$ & $80-616200$ \\
\hline GMPD & 2,110 & 8,793 & 56,742 & 7,754 & 11,053 \\
\hline
\end{tabular}

\section{Malaria parasite prevalence}

There was significant difference $(p<0.001)$ of prevalence of malaria infection among the four study military camps (Table 2). Recruits at Rwamkoma had the highest malaria prevalence by both microscopy (39.4\%) and mRDTs (38.6\%) while recruits in Bulombora had the lowest malaria prevalence by both microscopy (1.9\%) and mRDTs (1.4\%). The prevalence of malaria parasitaemia by both microscopy and mRDT was significantly higher among individuals aged $\leq 20$ years and females $(p<0.05)$. For microscopy, the prevalence was significantly higher among female recruits $(p=0.009)$, while those aged $\leq 20$ years had higher prevalence but the difference was not statistically significant (Table 2 ).

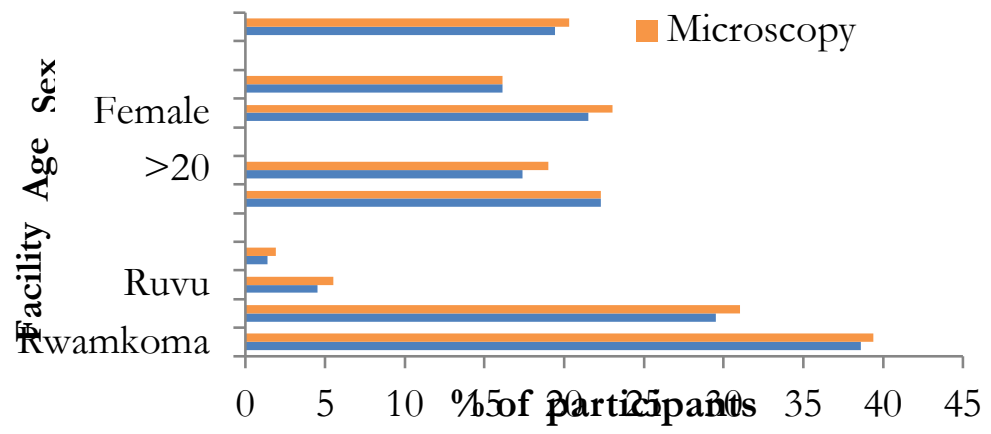

Figure 2: Malaria prevalence among study participants 
Table 2. Association between malaria parasite prevalence and demographic characteristics

\begin{tabular}{|c|c|c|c|c|c|c|c|}
\hline \multirow[t]{2}{*}{ Characteristics } & \multirow{2}{*}{$\begin{array}{l}\text { Total, } \\
\mathrm{n}(\%)\end{array}$} & \multicolumn{3}{|c|}{ RDT results } & \multicolumn{3}{|c|}{ Microscopy results } \\
\hline & & $\begin{array}{l}+\mathrm{Ve} \\
\mathrm{n}(\%)\end{array}$ & $\begin{array}{l}\text { Chi- } \\
\text { square }\end{array}$ & P-value & $\begin{array}{l}+\mathrm{Ve} \\
\mathrm{n}(\%)\end{array}$ & $\begin{array}{l}\text { Chi- } \\
\text { square }\end{array}$ & P-value \\
\hline \multicolumn{8}{|l|}{ Camp } \\
\hline Bulombora & $215(24.8)$ & $3(1.4)$ & 62.12 & $<0.001$ & 4(1.9) & 60.55 & $<0.001$ \\
\hline Mgambo & $200(23.1)$ & $59(29.5)$ & & & $62(31.0)$ & & \\
\hline Ruvu & $200(23.1)$ & $9(4.5)$ & & & $11(5 \cdot 5)$ & & \\
\hline Rwamkoma & $251(29.1)$ & $97(38.6)$ & & & $99(39.4)$ & & \\
\hline \multicolumn{8}{|c|}{ Age group (years) } \\
\hline$\leq 20$ & $350(40.4)$ & $78(22.3)$ & 3.13 & 0.047 & $78(22.3)$ & 1.40 & 0.237 \\
\hline$>20$ & $516(59.6)$ & $90(17.4)$ & & & $98(19.0)$ & & \\
\hline \multicolumn{8}{|l|}{ Sex } \\
\hline Male & $335(38.7)$ & $54(16.1)$ & 3.76 & 0.031 & $54(16.1)$ & 5.69 & 0.009 \\
\hline Female & $531(61.3)$ & $114(21.5)$ & & & $122(23.0)$ & & \\
\hline
\end{tabular}

\section{Comparison of mRDT with microscopy in diagnosis of malaria parasites}

Comparing to microscopy as reference test, the sensitivity of mRDT was found to be $76.1 \%(134 / 176)$ while the specificity was $95.1 \%(n=656 / 690)$. The positive predictive value and negative predictive value were $79.8 \%(n=134 / 168)$ and $94.0 \%(n=656 / 698)$ respectively. According to Cohen's kappa values there was moderate agreement (Kappa $=0.724$ ) between microscopy and mRDT test results of blood samples for malaria infection (Table 3)

Table 3: Comparison of performance of mRDT and microscopy in diagnosis $(n=866)$

\begin{tabular}{|c|c|c|c|c|c|}
\hline \multirow{2}{*}{ mRDT } & \multicolumn{2}{|c|}{ Microscopy } & \multirow{2}{*}{ Total, n (\%) } & \multirow{2}{*}{ Kappa } & \multirow{2}{*}{ P-value } \\
\hline & Positive, n (\%) & Negative, n (\%) & & & \\
\hline Positive, n (\%) & $134(76.1)$ & $34(4.9)$ & $168(19.4)$ & 0.724 & $<0.0001$ \\
\hline Negative, $\mathrm{n}(\%)$ & $42(23.9)$ & $656(95.1)$ & $698(80.6)$ & & \\
\hline Total, n (\%) & $176(20.3 \%)$ & $690(79.7)$ & 866.00 & & \\
\hline
\end{tabular}

\section{Relationship of malaria parasite densities with other parameters}

All recruits with malaria parasites detected by microscopy $(n=176)$, had parasite density ranged from 80 to 616,200 asexual parasites/ $\mu$ land the geometric mean parasite density (GMPD) was 11,053 asexual parasites/ $\mu$ l. Of all study camps, individuals from Mgambo (56.3\%) had the highest parasite densities (Table 4). Majority (56.8\%) of participants had parasite density ranging from 200 to 1,999 asexual parasites/ $\mu$ l of those from Bulombora (75\%), females (59.8\%) and those aged $>2$ oyears (61.2\%) had higher parasite densities at this range compared to others. Only $13.1 \%$ of the recruits had high parasite density ( $\geq 20,000$ asexual parasites/ $\mu$ l) (Table 4$)$

Table 4. Study participants with different levels of parasite density

\begin{tabular}{|c|c|c|c|c|c|}
\hline $\begin{array}{l}\text { Parasite density } \\
\text { (asexual para/ } \mu l \text { ) }\end{array}$ & $\begin{array}{l}<200 \\
N(\%)\end{array}$ & $\begin{array}{l}200-1,999 \\
n(\%)\end{array}$ & $\begin{array}{l}2,000-19,999 \\
n(\%)\end{array}$ & $\begin{array}{l}\geq 20,000 \\
n(\%)\end{array}$ & $\begin{array}{l}\text { Total } \\
\mathrm{N}(\%)\end{array}$ \\
\hline \multicolumn{6}{|l|}{ Camp } \\
\hline Bulombora & $0(0.0)$ & $3(75.0)$ & $1(25.0)$ & $0(0.0)$ & $4(2.3)$ \\
\hline Rwamkoma & $1(1.6)$ & $28(45.2)$ & $21(33.9)$ & $12(19 \cdot 3)$ & $62(35.2)$ \\
\hline Ruvu & $1(9.1)$ & $8(72.7)$ & $1(9.1)$ & $1(9.1)$ & $11(6.3)$ \\
\hline Mgambo & $1(1.0)$ & $61(61.6)$ & $27(27 \cdot 3)$ & $10(10.1)$ & $99(56.3)$ \\
\hline
\end{tabular}




\begin{tabular}{|c|c|c|c|c|c|}
\hline $\begin{array}{l}\text { Parasite density } \\
\text { (asexual para/ } \mu \mathrm{l} \text { ) }\end{array}$ & $\begin{array}{l}<200 \\
N(\%)\end{array}$ & $\begin{array}{l}200-1,999 \\
n(\%)\end{array}$ & $\begin{array}{l}2,000-19,999 \\
\mathrm{n}(\%)\end{array}$ & $\begin{array}{l}\geq 20,000 \\
\mathrm{n}(\%)\end{array}$ & $\begin{array}{l}\text { Total } \\
\mathrm{N}(\%)\end{array}$ \\
\hline \multicolumn{6}{|l|}{ Age group } \\
\hline$\leq 20$ & $2(2.6)$ & $40(51.3)$ & $25(32.1)$ & $11(14.1)$ & $78(44 \cdot 3)$ \\
\hline$>20$ & $1(1.1)$ & $60(61.2)$ & $25(25.5)$ & $12(12.2)$ & $98(55.7)$ \\
\hline \multicolumn{6}{|l|}{ Sex } \\
\hline Male & $2(3.7)$ & $27(50.0)$ & $21(38.9)$ & $4(7.4)$ & $54(30.7)$ \\
\hline Female & $1(0.8)$ & $73(59.8)$ & $29(23.8)$ & $19(15.6)$ & $122(69 \cdot 3)$ \\
\hline \multicolumn{6}{|l|}{ All groups } \\
\hline All & $3(1.7)$ & $100(56.8 \%)$ & $50(28.4 \%)$ & $23(13.1)$ & $176(100.0)$ \\
\hline
\end{tabular}

\section{Discussion}

To our knowledge, this is the first report on the prevalence of malaria infections among asymptomatic individuals in military settings of Tanzania. The study revealed high prevalence rates of asymptomatic malaria parasitaemia in military camps. The observed prevalence of asymptomatic carriers is presumably a result of high transmission rate in military camps because regular infection with $P$. falciparum results in partial immunity that favours the condition as studied by other authors(Diallo et al., 2012). A good proportion of asymptomatic carriers of parasites with no overt symptoms of malaria might be responsible for perpetuating transmission of malaria parasite in the presence of susceptible mosquitoes in the study areas as described previously (Nzobo et al, 2015; Sumari et al., 2017). Therefore, in the course of ongoing malaria elimination efforts in the country, there is a need to take into consideration for routine surveillance and encourage treatment of asymptomatic carriers to minimize infection rates.

Comparing the two diagnostic tests used, the prevalence rate of asymptomatic malaria parasite infection by Giemsa microscopy was slightly higher than that of mRDT. This finding is similar to what was reported in a study conducted in west Africa where asymptomatic infection cases were likely to be detected more by microscopy (10.5\%) compared to mRDT (9.3\%) (Gbalégba et al., 2018). Another study done in Nigeria also found higher prevalence by microscopy (25.95\%) compared to $22.90 \%$ and $15.20 \%$ of mRDT brands of Carestart and SD Bioline respectively (Ugah et al., 2017a). It seems mRDTs have lower detection ability in low parasitaemia samples that were detected by microscopy for the same samples as also described previously (Ugah et al., 2017a). Correspondingly, this study found high false negative rate (24\%) and low positive predictive value $(79.8 \%)$ by mRDT that was a result inability of to detect parasites in blood samples at lower densities (<200asexual parasites $/ \mu \mathrm{L}$ ) that were actually detected by blood slide. The reported low sensitivity among asymptomatic individuals is lower compared to that reported in a recent study done at Mgambo military camp among outpatients (Kalinga et al., 2018). Confidently, authors of this study associates the low sensitivity of mRDT with observed high false negativity rate of the test. Alternatively, although is uncommonly reported in Tanzania, false negativity rate reported in this study could be attributed by mutation of pfhrp2 and pfhrp3 gene (Gamboa et al., 2010) or by prozone effects as also reported (Kozycki et al., 2017).

The reported high malaria prevalence in this study was therefore associated with high parasite density; higher prevalence rate among recruits at Rwamkoma (39.4\%) and Mgambo (31.0\%), corresponded with higher proportions (35.2\% and 56.3\%) of individuals at the same camps who had higher parasite densities respectively compared to the rest of the camps. That means the detection rate of parasites using both microscopy and mRDT was higher among blood samples with high parasite densities compared to blood samples with low parasite density as described by other author (Drakeley et al., 2017).

Malaria parasitaemia prevalence was also observed to be higher in female adolescents than males as also described previously (Mazigo et al, 2010; Nzobo et al, 2015). This difference can presumably be due to general tendencies of female adolescents to commonly wear short dresses 
that do not cover lower parts of the legs hence are more likely to be exposed to mosquito bites compared to male adolescents who mostly wears trousers, stockings and shoes that provide protection of lower legs. Although this scenario may not be common in military settings, for some extent it might be happening especially during evening rest time. Although this study did not look on the Utilization of ITNs among recruits, it could also explain the difference in infection rates between the sex; underutilization has been reported to be associated with high infection rate (Dawaki et al., 2016; Yadav et al, 2014). Contrary to our finding, other authors have reported higher infection rates among males than females ( Li et al., 2013; Mazigo et al, 2017) and no association of infection rates with sex (Dawaki et al., 2016).

Considering that microscopy and mRDTs have limited ability to detect lower

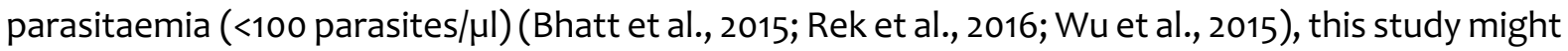
have underreported parasite reservoirs due to sub-microscopic infections and hence affecting the conclusion based on the findings. This study could have been improved by utilizing diagnostic tool with high sensitivity such Polymerase chain reaction (PCR) and loop-mediated isothermal DNA amplification which highly sensitive and specific and are considered as reference method to microscopy (Bourgeois et al., 2010)

In conclusion, this study reported high prevalence of malaria infections among asymptomatic recruits in selected military camps. The study has highlighted that public residence institutions such as military camps can be potential hotspots for malaria infection. As such, these institutions should not be skipped in routine national surveillance system to improve monitoring of malaria infections for evidence based planning of elimination interventions

\section{Ethical consideration}

The study was approved by the Medical Research Coordinating Committee of the Tanzania National Institute for Medical Research and the Ethics Review Committees of Kilimanjaro Christian Medical University College, Tanzania. It was also approved by the Walter Reed Army Institute of Research in the Silver Spring, Maryland, USA. The Tanzania Peoples Defence Forces (TPDF) headquarters and individual study camps granted permission prior to study commencement. To avoid any coercion, military staff and officers were not involved in recruiting participants and consenting process. Recruits who were found symptomatic and excluded from the study were tested and upon confirmed positive for malaria infection were treated. Similarly, asymptomatic individuals who were also confirmed positive for malaria infection were treated as per Tanzanian malaria treatment guidelines (NMCP, 2006)

\section{Competing interests}

Authors declare no competing interests

\section{Authors' contributions}

AKK and CM designed the study; AKK, SM, LT, RAK and SM drafted the manuscript. GBK, DSI, EK, CNM contributed to data analysis. AKK, DSI, RAK, CM, BV and EK revised the manuscript. KD, NW and $\mathrm{MH}$ reviewed and edited the manuscript. All authors read and approved the final version of the manuscript

\section{Acknowledgements}

The authors are thankful to US Walter Reed Army Institute of Research (WRAIR) for funding the main project in which this operational study was nested. The Commission for Science and Technology (COSTECH) in Tanzania and Fio Corporation in Canada are also acknowledged for providing financial support to Mr Akili Kalinga, the author who is pursuing PhD programme at Kilimanjaro Christian Medical University College (KCMUCo). Authors are indebted to Tanzania Peoples Defence Forces (TPDF) and the National institute for Medical Research (NIMR) in Tanzania and Henry Jackson Foundation Medical Research Institute (HJFMRI) for administrative support in 
the conduct of the study. We owe gratitude to the KCMUCo for hosting and supervising the student to accomplish his research milestones. Finally, Messers Zawadi Lubunga, Edward Kandole, Charles Nakomolwa, Fabian Ndihaye and Ms Emmaculata Msata are highly thanked for the laboratory work at the military health facilities

\section{References}

Bhatt, S., Weiss, D. J., Cameron, E., Bisanzio, D., Mappin, B., Dalrymple, U., ... Gething, P. W. (2015). The effect of malaria control on Plasmodium falciparum in Africa between 2000 and 2015. Nature, 526, 207. Retrieved from https://doi.org/10.1038/nature15535

Bourgeois, N., Boutet, A., Bousquet, P. J., Basset, D., Douard-Enault, C., Charachon, S., \& Lachaud, L. (2010). Comparison of three real-time PCR methods with blood smears and rapid diagnostic test in Plasmodium sp. infection. Clinical Microbiology and Infection, 16(8), 1305-1311.

Dawaki, S., Al-Mekhlafi, H. M., Ithoi, I., Ibrahim, J., Atroosh, W. M., Abdulsalam, A. M., ... Lau, Y.-L. (2016). Is Nigeria winning the battle against malaria? Prevalence, risk factors and KAP assessment among Hausa communities in Kano State. Malaria Journal, 15(1).

Diallo, A., Ndam, N. T., Moussiliou, A., Santos, S., Ndonky, A., Borderon, M., ... Hesran, J. Y. (2012). Asymptomatic carriage of plasmodium in urban Dakar: The risk of malaria should not be underestimated. PLOS ONE, 7(2).

Dicko, A., Sagara, I., Sissoko, M. S., Guindo, O., Diallo, A. I., Kone, M., ... Doumbo, O. K. (2008). Impact of intermittent preventive treatment with sulphadoxine-pyrimethamine targeting the transmission season on the incidence of clinical malaria in children in Mali. Malaria Journal, 7, 1-9.

Drakeley, C., Abdulla, S., Agnandji, S. T., Fernandes, J. F., Kremsner, P., Lell, B., ... Bahmanyar, E. R. (2017). Longitudinal estimation of Plasmodium falciparum prevalence in relation to malaria prevention measures in six sub-Saharan African countries NCT01190202 NCT. Malaria Journal, 16(1), 1-15.

Färnert, A., Yman, V., Homann, M.V., Wandell, G., Mhoja,L., Johansson,M., Jesaja,S., Sandlund,

J., Tanabe, K., Hammar, U., Bottai, M., Premji, Z.G., Anders Björkman, A. and Rooth, I.

(2015). Epidemiology of malaria in a village in the Rufiji River Delta, Tanzania: Declining transmission over 25 years revealed by different parasitological metrics. Malaria Journal, 1-12.

Gamboa, D., Ho, M. F., Bendezu, J., Torres, K., Chiodini, P. L., Barnwell, J. W., ... Cheng, Q. (2010). A large proportion of $\mathrm{P}$. falciparum isolates in the Amazon region of Peru lack pfhrp2 and pfhrp3: Implications for malaria rapid diagnostic tests. PLOS ONE, 5(1).

Gbalégba, C. G. N., Ba, H., Silué, K. D., Ba, O., Tia, E., Chouaibou, M., ... Koudou, B. G. (2018). Distribution of Plasmodium spp. infection in asymptomatic carriers in perennial and low seasonal malaria transmission settings in West Africa. Infectious Diseases of Poverty, 7(1), 1-13.

Gething, P. W., Battle, K. E., Bhatt, S., Smith, D. L., Eisele, T. P., Cibulskis, R. E., \& Hay, S. I. (2014). Declining malaria in Africa: Improving the measurement of progress. Malaria Journal, 13(1), 1-5.

Ishengoma, D. S., Mmbando, B. P., Segeja, M. D., Alifrangis, M., Lemnge, M. M., \& Bygbjerg, I. C. (2013). Declining burden of malaria over two decades in a rural community of Muheza district, north-eastern Tanzania. MW Journal, 4(19), 1-14.

Kalinga, A. K., Mwanziva, C., Chiduo, S., Mswanya, C., Ishengoma, D. I., Francis, F., ... Kavishe, R. A. (2018). Comparison of visual and automated Deki Reader interpretation of malaria rapid diagnostic tests in rural Tanzanian military health facilities. Malaria Journal, 17(1).

Kanté, A. M., Nathan, R., Helleringer, S., Sigilbert, M., Levira, F., Masanja, H., ... Phillips, J. F. (2014). The contribution of reduction in malaria as a cause of rapid decline of under-five mortality: evidence from the Rufiji Health and Demographic Surveillance System (HDSS) in rural Tanzania. Malaria Journal, (13:180), 1-9.

Kimbi, H. K. (2012). Asymptomatic Malaria in School Children and Evaluation of the Performance Characteristics of the Partec CyscopeHelen Kuokuo Kimbi, in the Mount Cameroon Region. Journal of Bacteriology \& Parasitology, 03(07).

Kozycki, C. T., Umulisa, N., Rulisa, S., Mwikarago, E. I., Musabyimana, J. P., Habimana, J. P., ... Krogstad, D. J. (2017). False-negative malaria rapid diagnostic tests in Rwanda: impact of Plasmodium falciparum isolates lacking hrp2 and declining malaria transmission. Malaria Journal, 16(1), 123.

Kweku, M., Liu, D., Adjuik, M., Binka, F., Seidu, M., Greenwood, B., \& Chandramohan, D. (2008). Seasonal intermittent preventive treatment for the prevention of anaemia and malaria in Ghanaian children: $A$ randomized, placebo controlled trial. PLOS ONE, 3(12).

Li, N., Parker, D. M., Yang, Z., Fan, Q., Zhou, G., Ai, G., ... Wang, Y. (2013). Risk factors associated with slide 
positivity among febrile patients in a conflict zone of north-eastern Myanmar along the China-Myanmar border. Malaria Journal, 12(1), 361.

Males, S., Gaye, O., \& Garcia, A. (2008). Long-Term Asymptomatic Carriage of Plasmodium falciparum Protects from Malaria Attacks: a Prospective Study among Senegalese Children. Clinical Infectious Diseases, 46(4), 516-522.

Mazigo, H.D., Rebecca Waihenya, R., Lwambo N.J., Mnyone, L.D., Mahande, A.M., Seni, J., Zinga, M., Kapesa, A., Kweka, E.J., Stephen E Mshana, S.E., Heukelbach, J., and Mmkoji, G. (2010). Research Co-infections with Plasmodium falciparum, Schistosoma mansoni and intestinal helminths among schoolchildren in endemic areas of northwestern Tanzania. Parasites \& Vectors, 3(44).

Mazigo, H. D., Rumisha, S. F., Chiduo, M. G., Bwana, V. M., \& Mboera, L. E. G. (2017). Malaria among rice farming communities in Kilangali village, Kilosa district, Central Tanzania: Prevalence, intensity and associated factors. Infectious Diseases of Poverty, 6(1), 1-10.

McHugh, M. L. (2012). Interrater reliability: the kappa statistic. Biochemia Medica, 22(3), 276-282.

Mehrizi, A. A., Zakeri, S., Safari, R., Raeisi, A., Kahanali, A., Turki, H., ... Zoghi, S. (2012). Survey for asymptomatic malaria cases in low transmission settings of Iran under elimination programme. Malaria Journal, 11(1), 126.

Mmbando, B. P., Vestergaard, L. S., Kitua, A. Y., Lemnge, M. M., Theander, T. G., \& Lusingu, J. P. A. (2010). A progressive declining in the burden of malaria in north-eastern Tanzania. Malar J, 9, 216. https:

MoHCDGEC, MoH [Zanzibar], NBS, OCG and ICF (2018). Tanzania Malaria Indicator Survey (TMIS) 2017:Dar es Salaam, Tanzania and Rockville, Maryland, USA.

NBS (TZ) \& Macro int. (2009). HIV/AIDS and Malaria Indicator Survey: Key Findings. Calverton, Maryland, USA: NBS and Macro International Inc.

Nkumama et al. (2017). Changes in Malaria Epidemiology in Africa and New Challenges for Elimination. Trends in Parasitology, 33(2), 128-140.

NMCP. (2006). National Guidelines for Diagnosis and Treatment of Malaria, (January), 1-105.

NMCP \& WHO, I. H. I. and the I. P. (2013). An epidemiological profile of malaria and its control in Mainland Tanzania.Report funded by Roll Back Malaria and Department for International Development-UK.

Nzobo, B.J., Ngasala, B.E., and Kihamia, C.M. (2015). Prevalence of asymptomatic malaria infection and use of different malaria control measures among primary school children in Morogoro Municipality, Tanzania. Malaria Journal, 14(1), 1-7.

Rek, J., Katrak, S., Obasi, H., Nayebare, P., Katureebe, A., Kakande, E., ... Greenhouse, B. (2016). Characterizing microscopic and submicroscopic malaria parasitaemia at three sites with varied transmission intensity in Uganda. Malaria Journal, 15(1), 1-8.

Singh, R., Godson, I. I., Singh, S., Singh, R. B., Isyaku, N. T., \& Ebere, U. V. (2014). High prevalence of asymptomatic malaria in apparently healthy schoolchildren in Aliero, Kebbi state, Nigeria. Journal of Vector Borne Diseases, 51(2), 128-132.

Sumari, D., Mwingira, F., Selemani, M., Mugasa, J., Mugittu, K., \& Gwakisa, P. (2017). Malaria prevalence in asymptomatic and symptomatic children in Kiwangwa, Bagamoyo district, Tanzania. Malaria Journal, 16(1), $1-7$.

TACAIDS, ZAC, NBS, OCG \& ICF (2013). Tanzania- 2011-12 HIV/AIDS and Malaria Indicator Survey 2011-12: Key Findings.

TACAIDS et al, 2013. (2013). Tanzania 2011-12 HIV/AIDS and malaria Indicator Survey: Key Findings.

Team, Q. D. (2018). QGIS Geographic Information System. Version 3.2 (Bonn). Open Source Geospatial Foundation Project. http://qgis.osgeo.org.

Ugah, U. I., Alo, M. N., Owolabi, J. O., Okata-Nwali, O. D., Ekejindu, I. M., Ibeh, N., \& Elom, M. O. (2017a). Evaluation of the utility value of three diagnostic methods in the detection of malaria parasites in endemic area. Malaria Journal, 16(1).

Ugah, U. I., Alo, M. N., Owolabi, J. O., Okata-Nwali, O. D. G., Ekejindu, I. M., Ibeh, N., \& Elom, M. O. (2017b). Evaluation of the utility value of three diagnostic methods in the detection of malaria parasites in endemic area. Malaria Journal, 16(1), 1-8.

WHO. (2010a). Basic Malaria Microscopy: Part 1. Learner's guide: Second Edition.

WHO. (2010b). Basic malaria microscopy: Part II. Tutor's guide. WHO Press, World Health Organization, 20 Avenue Appia, 1211 Geneva 27, Switzerland . ISBN 9789241547918 (Part 2).

WHO. (2010c). WHO Global Malaria Programme: World Malaria Report (Vol. 615).

WHO. (2016). World Malaria Report 2016. Retrieved from www.who.int/malaria

WHO. (2018). World Malaria Report. 2018. ISBN 9789241564694.

WHO \& UNICEF. (2015). Achieving the malaria Millennium Development Goal target: reversing the incidence of 
malaria 2000-2015. Geneva: WHO Global Malaria Programme:

Wu, L., van den Hoogen, L. L., Slater, H., Walker, P. G. T., Ghani, A. C., Drakeley, C. J., \& Okell, L. C. (2015). Comparison of diagnostics for the detection of asymptomatic Plasmodium falciparum infections to inform control and elimination strategies. Nature, 528(7580), S86-93.

Yadav, K., Dhiman, S., Rabha, B., Saikia, P.K., \& Veer, V. (2014). Socio-economic determinants for malaria transmission risk in an endemic primary health centre in Assam, India. Infectious Diseases of Poverty, 3(1), 1-8. 